\title{
Spiral Calcification in the Ventricular Myocardium
}

\author{
R. S. KIRK AND J. G. B. RUSSELL \\ From the Department of Pathology, Manchester University, and the Department of Radiology, \\ Manchester Royal Infirmary
}

Calcification in the ventricular wall is occasionally seen at necropsy. It is nearly always at the site of an old infarction, and other causes, which were reviewed by Shapiro et al. (1963), are rare. We present here two cases of what we believe to be a hitherto undescribed type of myocardial calcification in which there is selective calcification of certain of the muscle bands that make up the ventricular wall. These spiralling bands arise from, and are inserted into, the fibrous structures of the heart.

\section{CAse Reports}

Case 1. This patient, a man aged 56, developed angina and dyspnoea on exertion in May 1963. In July 1963 he was admitted to hospital as an emergency with acute left ventricular failure which responded to treatment. In September 1963 he had an attack of effort syncope in which he was unconscious for 3 minutes. During 1963 and early 1964 he had five attacks of paroxysmal dyspnœa with pulmonary œdema. There was no clear history of rheumatic fever, but he had had vague limb pains in his early teens and pain in the hips and knees at the age of 20 .

On examination there were signs of aortic stenosis. His blood pressure was $120 / 95 \mathrm{~mm}$. Hg. His electrocardiogram showed left bundle-branch block. The Wassermann reaction was negative, and the blood urea was repeatedly normal. Radiological examination (in 1963) had shown heavy ring calcification in the area of the aortic valve and an almost complete circle of calcification extending from this, which was thought to be a calcified atrio-ventricular ring. A stroboscopic tomogram (Russell, 1964) is reproduced in Fig. 1.

It was thought that he might have ischæmic heart disease in addition to aortic stenosis, and early in 1964 Mr. H. F. M. Bassett decided to carry out a limited valvotomy under hypothermia. At operation, the aortic valve was found to be bicuspid, heavily calcified, and grossly stenosed. It was dilated to $2.5 \mathrm{~cm}$. diameter. No aortic incompetence was noted after operation but signs of stenosis persisted. Subjectively he showed a

Received May 26, 1965. moderate improvement, but despite this apparently good result he had further attacks of left ventricular failure and died 10 months after operation.

At necropsy (performed at another hospital) the only abnormal findings were related to the cardiovascular system. The pericardial sac was almost entirely obliterated by fibrous adhesions. The lungs were congested and œedematous. The kidneys showed no gross scarring. There was no evidence of metastatic calcification.

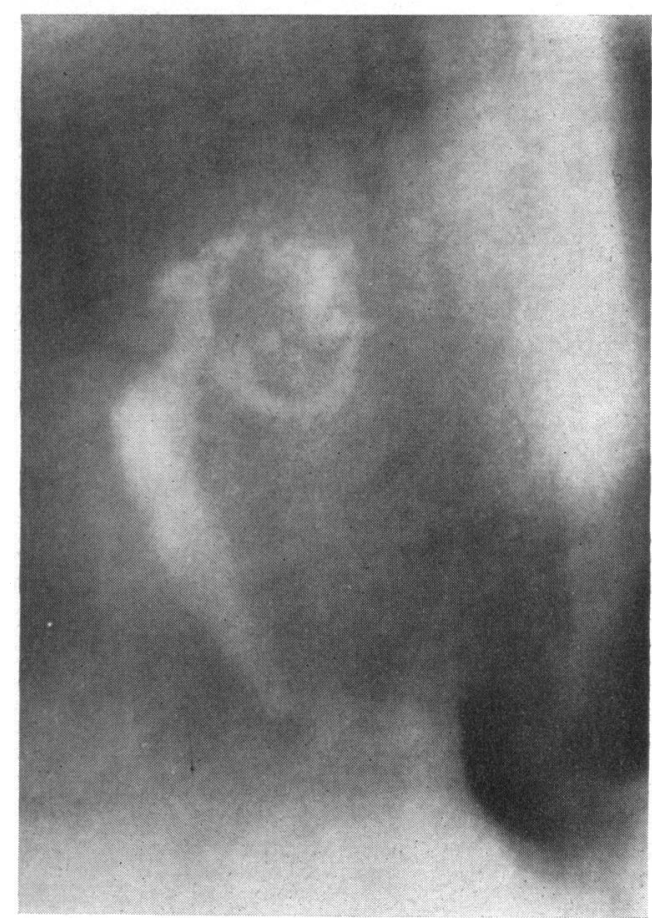

FIG. 1.-Case 1. Stroboscopic tomogram, taken in the left lateral projection, showing the calcified ring of the aortic valve, and contiguous with this the calcific band passing round the ventricular wall inferiorly. Only part of it is seen on this tomographic cut. 


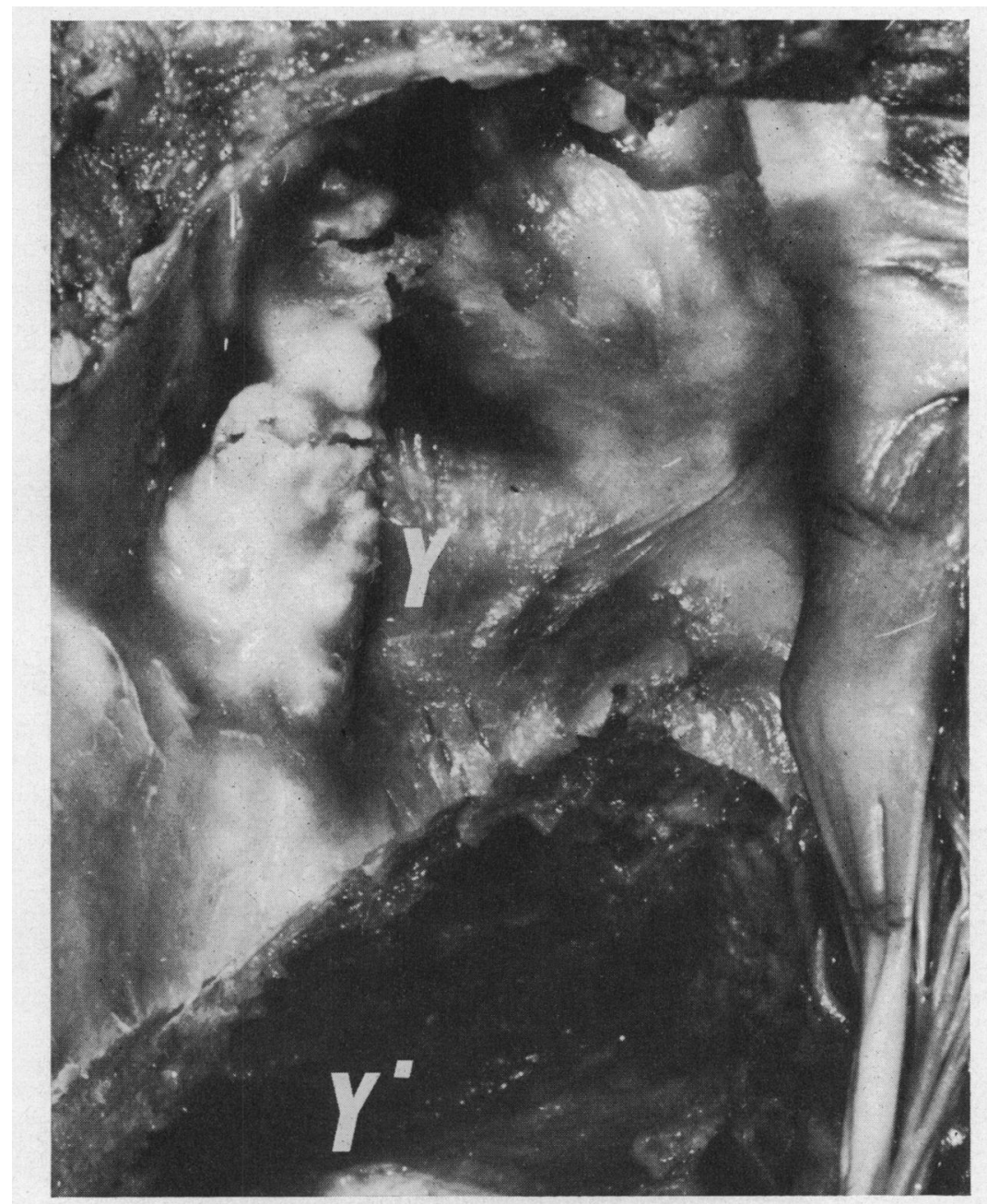

FIG. 2.-Case 1. The endocardial bar $(\mathrm{Y})$ extends down from the aortic valve and penetrates into the myocardium $\left(\mathrm{Y}^{1}\right)$.

The heart was enlarged and weighed $750 \mathrm{~g}$. There was a marked hypertrophy of the left ventricle with dilatation, and a slight hypertrophy of the right ventricle with dilatation. The left and right ventricular myocardium measured 16 and $7 \mathrm{~mm}$., respectively, $3 \mathrm{~cm}$. below the atrio-ventricular ring. The endocardium was pale brown and there was no evidence of thickening. The tricuspid and pulmonary valves were normal. The mitral valve showed a minimal diffuse thickening of the cusps compatible with the normal changes of the ageing valve. The chordæ tendinex were normal. The aortic valve cusps were thickened, calcified, and rigid with a central opening approximately $27 \times 7 \mathrm{~mm}$. The valve was bicuspid in type with a larger postero-lateral cusp, which was partially divided into two parts by a median raphe that did not extend to the full height of the cusps. The valve cusps were separated almost to the aortic attachments. Extending down vertically from the right posterior commissure was a calcified bar. For $3 \mathrm{~cm}$. it lay inferior to the membraneous part of the interventricular septum (Fig. 2). It gradually sank into the ventricular myocardium and then turned to run, within the myocardium, in continuity round the lateral and inferior sides of the left ventricle, approximately $4 \mathrm{~cm}$. on the ventricular side of the atrio-ventricular ring (Fig. 3). The calcification terminated in a blunt point $2 \mathrm{~cm}$. short of the left margin of the interventricular septum; thereafter a poorly localized fibrous band continued for approximately $1 \mathrm{~cm}$. further and then ceased. At no point in its ventricular course did the calcification come into contact with endocardium or pericardium. In most places it measured approximately $1 \mathrm{~cm}$. in diameter, but in its middle part it showed areas of broadening with occasional short outbranchings. This is shown in the 
post-mortem radiograph (Fig. 4). There was fibrosis round the calcific band, and there were small focal areas of fibrosis of the upper anterior part of the left ventricle. The right ventricle appeared macroscopically normal. The coronary arteries showed prominent focal plaques of atheroma involving approximately 60 per cent of the surface, but at no place were the arteries narrowed. The ascending aorta and the aortic sinuses were free from atheroma.

Microscopy. The area of calcification showed granular deposits of amorphous calcific material with a surrounding fibrosis which was encircling islands of surviving muscle cells. Some of the latter appeared small and atrophic. There were no inflammatory cell infiltrations. Stains for iron were negative. In occasional areas, surviving muscle cells appeared to be in the process of being calcified (Fig. 5). There was no evidence of muscle necrosis. The left ventricular myocardium away from the calcified area showed a moderate degree of focal interstitial fibrosis. The muscle cells were hypertrophied. The right ventricular and interventricular septum showed very occasional focal areas of interstitial fibrosis. The aortic valve ring and cusps were vascularized. There was no evidence in any of the sections examined of active rheumatic disease.
Case 2. This man, aged 44, was first seen at this hospital in 1957. He had a history of chronic bronchitis and emphysema for 20 years. The radiological appearances showed bilateral bronchiectasis. Since 1962 he had had episodes of right ventricular failure and the electrocardiogram showed changes of cor pulmonale. A diagnosis of systemic lupus erythematosus was made in 1964, and L.E. cells were demonstrated on several occasions after that. He had clinical and radiological evidence of rheumatoid arthritis of the hands and feet. Sheep cell agglutination tests were positive, but tests for antinuclear factor were repeatedly negative. His serum proteins showed a marked increase in the $\gamma$ globulins. There was no clinical episode suggestive of cardiac infarction, and his electrocardiogram showed no evidence of ischæmic heart disease. The Wassermann reaction was negative. The blood urea has always been within normal limits.

Cardiac calcification was seen on the plain films in 1957 (Fig. 6). Stroboscopic tomograms had shown more details (Fig. 7). There was an elliptical ring of calcification. This differed from the usual appearance of a calcified atrio-ventricular ring, being narrower and extending upwards in a smooth curve not seen in atrioventricular ring calcification. This was the path taken 


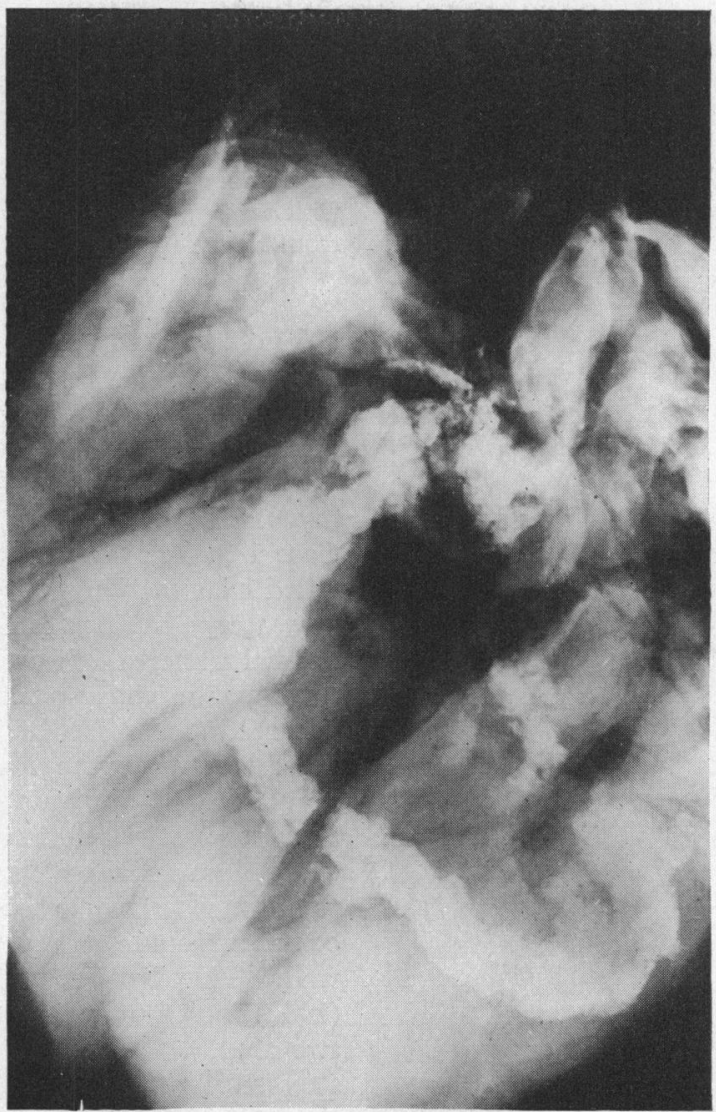

Fig. 4.-Case 1. Post-mortem radiograph showing the extent of the calcification.

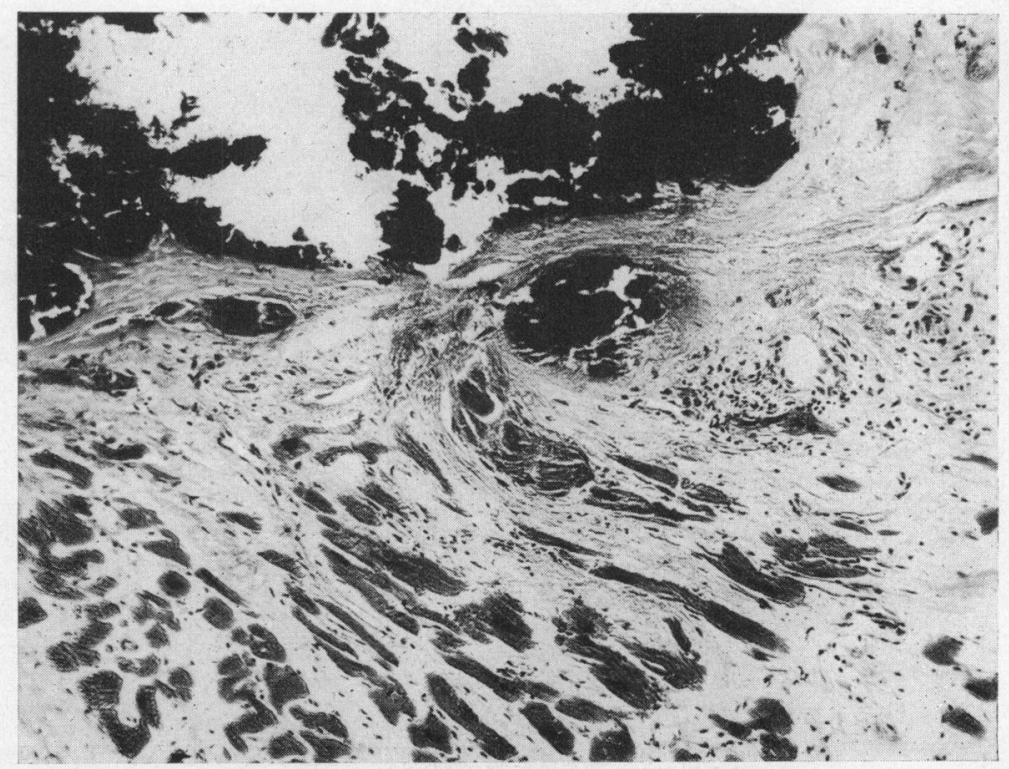

FIG. 5.-Case 1. Microscopical appearance of the calcific band showing the surrounding interstitial fibrosis with calcification of muscle fibres. (H. and E. $\times 100$.) 


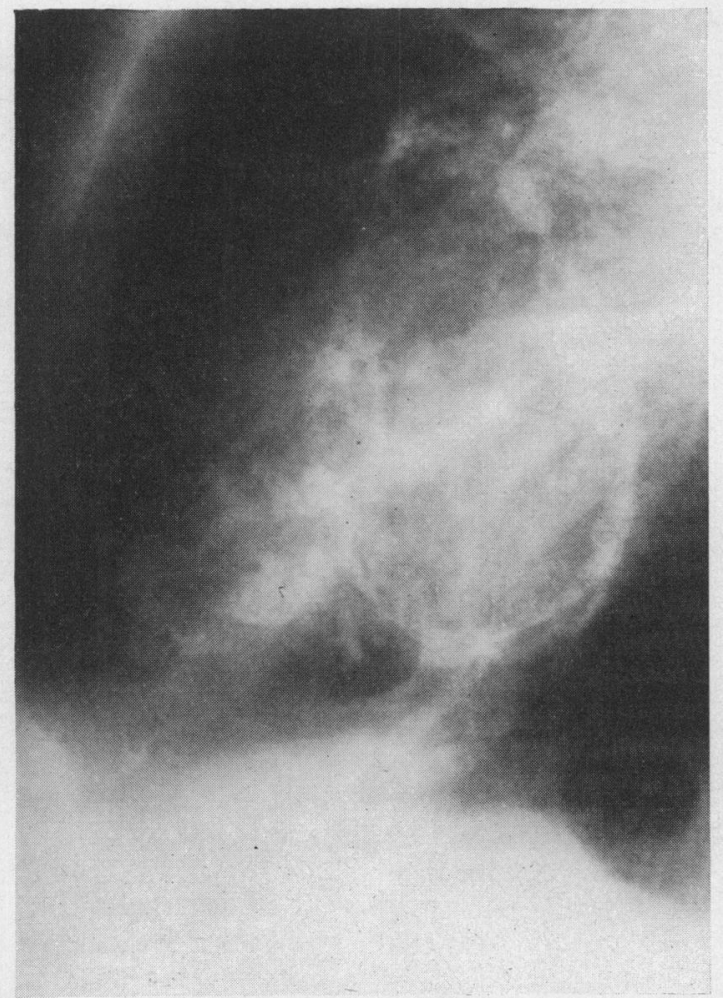

FIG. 6.-Case 2. Left lateral plain film of the heart showing the intracardiac calcification. The large elliptical shadow passes higher than an atrio-ventricular ring.

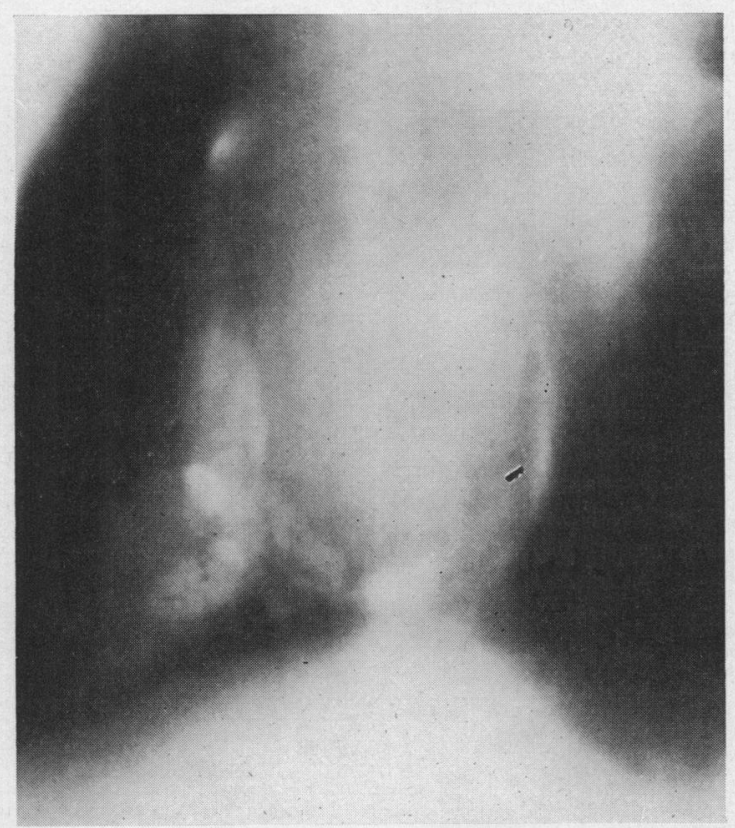

FIG. 7.-Case 2. Stroboscopic tomogram showing more clearly the whorled calcification lying in the right hand wall of the ventricle. by the deep bulbo-spiral muscle, which enclosed the mitral orifice, and swept up to surround the aortic outflow tract. In addition, there were two quite unusual whorled calcifications which the tomograms showed to be lying in the right side of the left ventricular wall. These corresponded to the superficial sino-spiral muscle which ran spirally down the ventricular wall in this area, from the atrio-ventricular annulus (Fig. 8).

\section{Discussion}

These two cases, though showing calcification of different sites in the ventricular wall, appeared to be similar in the unusual linear deposition of the calcium.

We can find no previously published reports of myocardial calcification of this distribution. In Case 1 (where the heart has been available for detailed examination) it is completely separate from any artery or vein; neither does it follow any of the normal patterns of distribution of vascular, lymphatic, or nervous elements. It is too linear to have occurred as a result of ischæmia, and it is widely separated from the atrio-ventricular ring. The regular shape and uniform deposition of calcium suggest that it is following some natural band or channel, and the only such structures which seem to fit the pattern are the muscle bands. These, in a complex manner, interweave to form the ventricular wall. They have been divided by Robb and Robb (1942) into four main groups; two superficial and two deep. Their pathological importance has been stressed by Wartman and Souders (1950) who showed that there could be a differential involvement of these muscle bundles in myocardial infarction. They have not, however, shown a selective muscle necrosis which could in any way correspond to the distribution of the lesion we report.

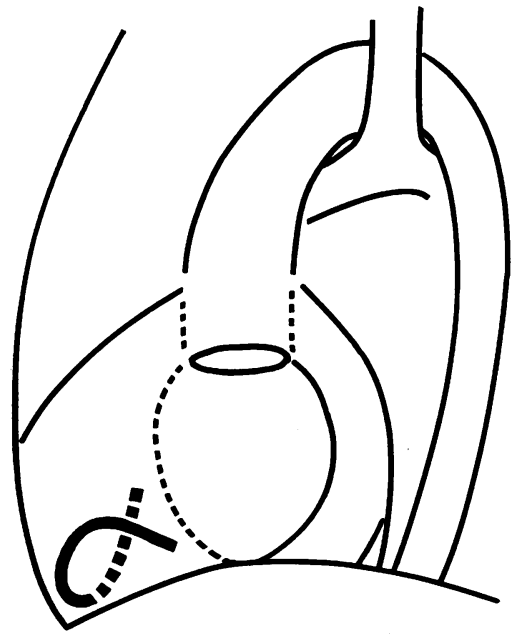

Fig. 8.-Case 2. Diagram redrawn from Robb and Robb (1942) to show part of the path of the superficial sino-spiral muscle. Compare with Fig. 7. 
In Case 1 the area affected corresponds to one of the deep group of muscle bundles arising from the atrio-ventricular annulus to make a double spiral in the wall of the left ventricle before terminating in the anterior part of the aortic ring (Fig. 9) Calcification in this case occurred in the first spiral. In Case 2 two groups appear to be involved. In one, i.e. the deep bulbo-spiral, it seems that an entire bundle is involved. In the other, i.e. the superficial sino-spiral, probably smaller lengths of more than one bundle are calcified.

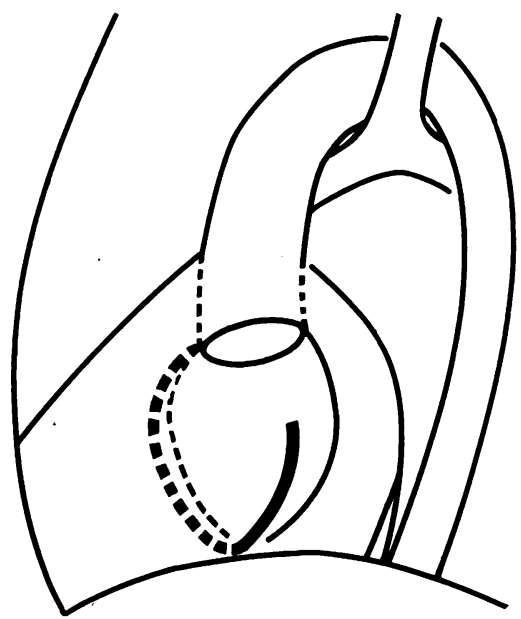

FIG. 9.-Case 1. Diagram redrawn from Robb and Robb (1942) showing the path of the muscle band which has calcified. In this left lateral view the part of the atrio-ventricular ring (thin line) and muscle bundle (thick line) shown on the far side of the heart are drawn as an interrupted line. Compare with Fig. 1.

Myocardial calcification was described by Morgagni (1762) and was first noted radiologically by Scholz (1924). Earlier reports have recently been reviewed by Testelli and Pilz (1964). Gore and Arons (1949) have described two groups, dystrophic and metastatic, the former being considerably more frequent. There was no evidence of metastatic calcification in other sites in Case 1, and there were no biochemical findings in either case to suggest it. We believe, therefore, that the lesion in our cases is dystrophic in nature, though there was no evidence of renal failure which is said to be present in most cases of myocardial calcification.

It is impossible to explain with certainty the processes in these two cases, which have resulted in myocardial calcification. It seems probable that the calcification can only have occurred secondarily to some (possibly necrotic) change in the myocardial muscle, which has predominantly involved selected muscle bands. Many ætiological factors have been suggested as a cause of myocardial calcification, including renal failure, hypokalæmia (Littman and Meadows, 1963), cardiac surgery (Hermann, Haupt, and Birkhead, 1963), toxic and septic factors (Ernstene and Hazard, 1951; Diamond, 1932); in a few cases no obvious cause has presented (Duke, 1957). Calcification of the myocardium presenting in adult life could occur as a result of muscle necrosis in early life. Hamne and Ranström (1957) cited evidence to show that myocardial infarction occurring in children was especially likely to be followed by calcification. They described two cases of focal myocardial calcification in infants secondary to muscle necrosis of uncertain cause, with no evidence of myocarditis and no narrowing of coronary arteries. In their descriptions of the hearts, they stressed that in both cases the areas of focal muscle necrosis were distributed in a linear fashion parallel to the endocardial surface and mainly involving the inner third of the muscular wall. They discussed the relationship to congenital endocardial fibrosis. In none of these recorded cases was the calcification localized to individual muscle bands, but it is possible that the cases we report are the end-result of such disease processes in individual muscle bands, with subsequent calcification. The significance of the lupus erythematosus in our Case 2 is impossible to assess. It must be stressed, however, that the calcifications were present for at least three years before the diagnosis of systemic lupus erythematosus was made, and they do not appear to have progressed over the period.

The experimental production of cardiopathies with calcification has been recorded in several papers (Selye, 1958; Prioreschi and Selye, 1961; Bajusz and Jasmin, 1963). They have shown that there is no single mechanism and that it can occur as a result of many complex pathogenic situations, in which hormonal influences and stress play an important part. None of these experimental situations seem applicable in the present instance and in no report is the calcification described as occurring along muscle bands, as in our cases.

The significance of the aortic stenosis in Case 1 is difficult to assess. Calcific aortic stenosis occurs relatively frequently and its ætiology has been widely debated. Karsner and Koletsky (1947) showed that almost all cases were the result of rheumatic heart disease.

There are several possibilities in the light of the relevant information. The first is that the aortic valve and myocardial calcifications have two different ætiologies with only a secondary joining of the calcific processes. A second (and more speculative) possibility is that they have a related ætiology in that the myocardial calcification is secondary to the 
aortic valve calcification by a process of extension onto the endocardium and thence into the muscle. The calcified muscle band involved in Case 1 originates from the aortic ring at the approximate site of the calcified endocardial bar extending down from the aortic valve. This bar can be reasonably ascribed to a calcified area of endocardial thickening occurring as a result of local turbulence at the commissure. The development of these "jet" lesions was described by Still (1961). There are many references to the spreading of calcification from pericardium and endocardium to involve the myocardium, possibly by a pressure necrosis of muscle with subsequent expansion of the calcified area. Calcific involvement of the membranous part of the interventricular septum secondary to calcareous aortic stenosis, with the development of conduction defects, was noted by Boas (1935), and the radiological appearances were discussed by Windholz and Grayson (1947). It is of interest to note in this respect the left bundle-branch block in Case 1 . Mitral ring calcification with involvement of adjoining myocardium and to a lesser extent the membranous septum was described by Korn, DeSanctis, and Sell (1962), but their description and our personal observations (unpublished) suggest that the primary lesion could well be, in part, the result of calcification of organized thrombi in the subvalvular angle of the mitral valve. Several cases of extension of calcification from a calcified pericardium, with involvement of the underlying muscle, were mentioned by Scholz (1924) in his review of myocardial calcification. By a similar analogy to the foregoing examples, it seems possible that the subaortic calcification could have spread to involve the muscle bands originating in this area. It seems possible that the calcified aortic valve acted as a "starter" and that the calcification proceeded by extension and accretion along the muscle band, in which, it must be remembered, the fibres are in a syncytial network. It is unlikely that the calcification would extend along normal muscle, and possibly the myocardium was damaged by previous disease, the calcification spreading along this particular band as a result of its anatomical relationship to the calcific "starter". In Case 2 there is no calcific aortic stenosis, but it is possible that there was somewhere a focus of calcification that could act as a "starter" in a similar manner.

The clinical effect of these calcifications is uncertain. The degree of disturbance to ventricular systole would depend on the site and extent. A calcified, relatively unyielding, rod-like structure lying in the ventricular wall would embarrass the contractile effort more than a local rigidity, such as occurs in a healed cardiac infarct. The poor result of the valvotomy in Case 1 may have been partly due to such interference with ventricular function.

It is of interest to note that in some of the larger mammals bones may develop in the heart-the ossa cordis. In the cow these reach $4 \mathrm{~cm}$. in length, but they are bony condensations in the fibrous skeleton round the aortic valve rather than in the myocardium (Sisson, 1953).

The antemortem diagnosis of the condition depends on radiology. Several sites of cardiac calcification give crescentic shadows, in particular calcification of the fibrous skeleton of the heart in the region of the mitral ring. Coronary artery calcification and calcification of organized thrombi in the mitral subvalvular angle are also seen. The latter we believe to be commoner than is generally recognized, being frequently wrongly described, even at necropsy, as mitral ring calcification. In Case 1 we cannot differentiate the radiological appearances seen from those of atrio-ventricular ring calcification, even in retrospect. The only feature to note is the almost smooth outline which has not been observed in our experience in atrio-ventricular rings. The radiological diagnosis can only be presumed if the distribution is such as to conform with the anatomy of a known muscle group sufficiently far away from the atrio-ventricular ring, as in Case 2.

\section{SUMMARY}

We record a form of myocardial calcification which we believe has not been previously described. In one case the findings at necropsy were available, and in the second case the diagnosis has been advanced on the unusual radiological appearances.

The anatomy of these calcifications is described, and the possible ætiology and clinical significance are discussed.

We should like to thank Professor A. C. P. Campbell and Dr. E. D. Gray for their encouragement and assistance, Mr. H. F. M. Bassett, Dr. C. S. D. Don, and Dr. A. Morgan Jones, the consultants in charge of the cases, Dr. R. M. Winston of Hope Hospital, Salford, who kindly provided details of the necropsy of Case 1 , and Dr. R. Ollerenshaw of the Department of Medical Illustration, Manchester Royal Infirmary, and Messrs. N. Mowat and J. T. Stopford of the Department of Pathology, Manchester University, for the illustrations.

\section{REFERENCES}

Bajusz, E., and Jasmin, G. (1963). Studies on factors that selectively influence calcification in the myocardium. Cardiologia (Basel), 43, 104.

Boas, E. P. (1935). Angina pectoris and heart block as symptoms of calcareous aortic stenosis. Amer. F. med. Sci., (n.s.), 190, 376.

Diamond, M. (1932). Calcification of the myocardium in a premature infant. Arch. Path., 14, 137. 
Duke, M. (1957). Massive calcification of the myocardium of unknown origin. Arch. Path., 64, 34.

Ernstene, A. C., and Hazard, J. B. (1951). Extensive calcification of the myocardium. Report of a case. Circulation, 3, 690 .

Gore, I., and Arons, W. (1949). Calcification of the myocardium. A pathologic study of thirteen cases. Arch. Path., 48, 1.

Hamne, B., and Ranström, S. (1957). Calcification of the heart muscle in infants. Acta path. microbiol. scand., 41, 111.

Hermann, G., Haupt, G. J., and Birkhead, N. C. (1963). Rapid myocardial calcification after cardiac surgery. F. Amer. med. Ass., 186, 260.

Karsner, H. T., and Koletsky, S. (1947). Calcific Disease of the Aortic Valve. Lippincott, Philadelphia.

Korn, D., DeSanctis, R. W., and Sell, S. (1962). Massive calcification of the mitral annulus. A clinicopathologic study of 14 cases. New Engl. F. Med., 267, 900.

Littman, M. S., and Meadows, W. R. (1963). Massive myocardial necrosis with calcification. Report of two cases of possible hypokalemic etiology. Circulation, 28, 938.

Morgagni, G. B. (1762). De Sedibus et Causis Morborum. Epist. 27, art. 16.

Prioreschi, P., and Selye, H. (1961). A calcifying cardiopathy produced by stress and calcium acetate. Brit. $\mathcal{F}$. exp. Path., 42, 135.
Robb, J. S., and Robb, R. C. (1942). The normal heart. Anatomy and physiology of the structural units. Amer. Heart f., 23, 455.

Russell, J. G. B. (1964). Stroboscopic tomography of the heart. Brit. F. Radiol., 37, 440.

Scholz, T. (1924). Calcification of the heart: Its roentgenologic demonstration. Arch. intern. Med., 34, 32.

Selye, H. (1958). The Chemical Prevention of Cardiac Necrosis. Ronald Press, New York.

Shapiro, J. H., Jacobson, H. G., Rubinstein, B. M., Poppel, M. H., and Schwedel, J. B. (1963). Calcifications of the Heart. Thomas, Springfield, Illinois.

Sisson, S. (1953). The Anatomy of the Domestic Animals, 4th ed., revised by J. D. Grossman. W. B. Saunders, Philadelphia.

Still, W. J. S. (1961). Endocardial thickening associated with diseased valves. Brit. Heart F., 23, 155.

Testelli, M. R., and Pilz, C. G. (1964). Massive calcification of the myocardium. A report of two cases, one associated with nephrocalcinosis. Amer. F. Cardiol., 14, 407.

Wartman, W. B., and Souders, J. C. (1950). Localization of myocardial infarcts with respect to the muscle bundles of the heart. Arch. Path., 50, 329.

Windholz, F., and Grayson, C. (1947). Roentgen demonstration of calcifications of the interventricular septum in cases of heart block. Amer. F. Roentgenol., 58, 411. 